Perdana, I., Manullang, S. O., \& Masri, F. A. (2021). Effectiveness of online Grammarly application in improving academic writing: review of experts experience. International Journal of Social Sciences, 4(1), 122-130. https://doi.org/10.31295/ijss.v4n1.1444

\title{
Effectiveness of Online Grammarly Application in Improving Academic Writing: Review of Experts Experience
}

\author{
Indra Perdana \\ Universitas Palangka Raya, Indonesia \\ Email: indra.perdana@fkip.upr.ac.id \\ Sardjana Orba Manullang \\ Universitas Krisnadwipayana, Indonesia \\ Corresponding author email: somanullang@unkris.ac.id \\ Fina Amalia Masri \\ Universitas Halu Oleo, Indonesia \\ Email:fina_amalia@uho.ac.id
}

\begin{abstract}
This study aims to discuss the effectiveness of the Grammarly online application in improving academic writing through the experience of reviewing published papers. For that, we have reviewed a variety of literature and listened to the experiences of other academics published in various international journals. We chose descriptive qualitative content analysis. For example, it involves an in-depth analysis of each expert's experience with an exploratory phenomenological approach. To do this, we involve a coding analysis system, critically evaluate the content and ensure the results are valid and reliable. As for literature sources, we do with the help of the Google Doc application, Eric Publications, Google scholars, and other online literature sources. We do this considering that we did this study in a dynamic era and responded to the pandemic protocol and public restriction in Indonesia. We follow the guidelines of descriptive qualitative studies experts in academic writing and application technology. The result is that most academics say that the Grammarly online application is very suitable for use by writers because its usefulness is beneficial in tracking writing errors.
\end{abstract}

Keywords---academic writing, authorship support, grammarly application, qualitative review.

\section{Introduction}

Before talking a little further, let us first understand what implementing online Grammarly does for a writer. As we know, Grammarly checker software is an application that is used as a writing aid to support writers in checking for various types of language errors or grammar errors in English. Ghufron (2019) said that Grammarly checker has a role in assessing English writing mistakes. An elementary understanding of Grammarly's text work is to check the text's spelling and then keep the tool's aim to keep typos out of context. So, it is an application that controls, maintains, and maintains writing production to look right. So there will be more errors, and then it also provides free plagiarism checks. Can detect errors in the academic field, such as plagiarism or data similarity from other onlinebased data. So, Grammarly software does well while comparing to see similarities. Concerning the above idea, Bailey \& Lee (2020) also said that Grammarly checker software is relevant in the English writing learning context (Lassoued et al., 2020).

A basic understanding of the functions of the Grammarly tool is to check for errors in written English. Its purpose is to keep typos out of context. So this application controls or maintains the flow of writing correctly so that no more errors come out (Qassemzadeh \& Soleimani, 2016). Grammarly also provides writing assistance to correct grammar errors and word spelling and is free from plagiarism. This tool can also detect lousy behavior among academics, such as plagiarism, by looking at and checking other written data available online. So, this software Grammarly compares 
with other online-based data detecting to see similarities. Then Grammarly did, and it is based on the experience they like to check writing style. It will support writers such as automatic editing with real-time live-in feedback, which makes skip tags like is understand communication very well. Sometimes, the Grammarly application gives correcting errors, then yes, it adopts a specification model or writing style for what the author is doing. So academic or business writers can choose the style and purpose of writing. All destinations as selected is up to the writer. It all depends on what the user has set to be professional or personal, such as writing language for email and other social networking (Zhang, 2020; Manullang \& Satria, 2020).

In addition to what the Grammarly application software provides support, this tool also provides a grammar check that is very useful for writers such as online activists with automatic direct support, such as bloggers for work outside academy assignments or business people presentations and doing email or others (Barrot, 2020). Writing on social networks is also possible for students and anyone who enjoys and wants to be effective at writing English. However, as an academic, they have to choose something like formal English with an academic writing system and bound by a formal writing system. So the writer must be like a correct punctuation mark presented by the Grammarly application and then for those who like academics and have a particular target and foundation in academia. So this Grammarly tool is what the authors say is used more by people outside of English-speaking countries. It is true that many people, also then Americans and several other British countries such as UK, Canada, and Australia use this practical grammar application. Even native English speakers or writers use this Grammarly check tool. This tool is designed to establish better English writing. So there is no reason to claim that native English speakers have better academic writing skills without using online academic writing apps nowadays. Like an automatic online writing check tool used for large communities no matter native speakers or non-native English speakers. This is true since the advent of various automatic grammar checkers (Cavaleri \& Dianati, 2016; Amelia \& Abidin, 2018).

Another question can also be like the two features; one Grammarly for free and Grammarly for a premium price. Then the premium version, because it is paid, there is a difference between the limit and the unlimited service (Cavaleri \& Dianati, 2016). The free version seems very limited in that the application only shows mistake areas but does not provide the automatic correction. Grammarly's premium version identifies errors and provides free corrections with easy-to-click operation on highlighted areas. For this premium app, Grammarly works very fast by automatically providing corrections. Its automaticity is also much helped according to the author's internet connection speed. So this is different from most of us who work in the professional sector using such as grammar for business which also offers various practices so that writers are speedy and make writing products look outstanding.

So we can also provide this application online, or users like to adjust what type of writing is being done. The author, for example, is writing to send this work for a matter of minutes so they will efficiently work with practical suggestions from the Grammarly application. Authors can also set options like doing purpose writing for informal or formal contexts. Qassemzadeh \& Soleimani (2016) also that the benefits of feedback provision by Grammarly application and instructors on learning active structures. Then profile so it means language like English likes information or writers can take turns to describe or want convincing or storytelling to trick the writer. The app also advises whether it for the general or knowledgeable person paper or media expert is the part of Grammarly's work relevant to improving academic writing.

Not for users who are new to this Grammarly tool, this tool can provide users an efficient way to operate this tool, how to use this tool virtually even for new users like juniors who are not very skilled in this Grammarly tool (Susskind \& Susskind, 2015; Taylor, 2016; Chen et al., 2020). They also said that educators' future is also influenced by technology that will transform academic and other human expertise. Writers can choose from a multitude of can copy and paste material articles about anything and then put and pick them up straight away for spelling or grammar. Users to read or anything like the property of other supporters and other options can be like not importing so that the author can make such a big mistake and then check together. However, sometimes it seems like it works a little bit slow compared to others. Like for example, a single page of material to go through quickly. Băutu \& Băutu (2020) said that the improvement on PlagZap, the fast and free academic work plagiarism detection method in higher education. Grammarly works on importing files from Microsoft Word documents and then inserting them into Grammarly and other options the user can also do using applications such as writing. It is like a genuine writer, but more writers use the one option copy and paste and see suggestions or check what the author gives.

Writers usually experience suggestions and correction options from Grammarly, even minor improvement suggestions. Ventayen \& Orlanda-Ventayen (2018), Wilmore \& Willison (2016) with the study the graduate students' understanding of the utilities of Grammarly in academic. The writing looks good and is free of grammatical errors, such as errors that occur automatically so that the author does not have time to correct them. Grammarly also checks and modifies errors through documenting and making more corrections, or most of the corrections take a long time without the advice of this app. This error usually occurs as a result of the author's negligence. However, if the 
author chooses not to agree with it, then the writer can use the button. So, Grammarly premium app profile suggestions are more detailed than the free ones, so in terms of mystique like errors or language functions in sentence structure so this is very, very useful for us like nonnative English where they have good knowledge but they are not good at writing so this tool is beneficial, but when the author is not too good at evaluating language. Parra (2016) did see an automated writing correction application in the development of the writing exercises (Ellingson \& Noe, 2017; Xie \& Yang, 2020; Hiremath \& Patil, 2020). Similarly, these Grammarly tools can help writers even if they offer writers with necessary grammar checks or these tools work with passive advice if writing is a little more verbose, or they can provide a correction of something easy for readers to understand.

Apart from easy corrections, Grammarly also provides spell checking. It automatically provides the user with more choices to do for the vocabulary and even gives the user a score if the writing is good enough. Grammarly gives a score of up to 99 points (Cavaleri \& Dianati, 2016; Koltovskaia, 2020). However, if the writer has terrible writing, they only get a score of about 50, then correct it to be the highest. So writing is an estimate that the tool has had time to analyze the text's content and initiate new sentence corrections. This Grammarly tool also detects the similarities of millions of website contents freely, so the author likes to detect writing similarities, such as plagiarism. They can provide the library's instant text, and writers can remember or reach out to operate it. That is how to get home to work with similar texts from millions or online websites. This tool, wherever the author is on the web for mobile Grammarly, can do parallel writing in the author's name. So users can also use social media on social media, Google translate. A grammar application can go into many applications that work for users with editing services in many ways (Akorede, 2020a; Xie, 2019).

Syafi'i (2020) noted, Grammarly software is an automatic online tool to support English writing. The Grammarly application wants to connect the writer with grammar software that can provide assistance services when the writer wants to improve academic papers in English or other writing goals. So it can be said that this Grammarly is for writers for scientific or academic journal purposes. So when the author is working on academic writing, let us say in academic English, of course, there are several ways or knowledge that journal writers still need. This is important for improving academic writing in many ways. For example, there are two kinds of language styles and styles; active or passive language. The writer needs one more dominant writing with an active voice (Kaushik et al., 2020). There are times when the writer also uses the passive voice, but the author himself prefers to have a more active voice sentence pattern because he feels the author's mind is more robust when using active voice; for example, the writer's presence mind there is powerful. Therefore, the author prefers to follow the Grammarly application directions by using tools to support the author in many contexts and problem content.

The sound design style is passive or active when the writer is confused about which one to choose, then the presence of Grammarly's suggestions will help writers who have to pay attention to what if a wrong choice sometimes results in misunderstanding and can reduce the quality of writing (Finlay, 2020; Wingate \& Harper, 2021). Naturally, the writer is obliged to know which one is correct. If I can get it right without the help of tools, this is good enough. What if junior writers, of course, quickly know which one is suitable. The author looks like that and the writing style if the user can get the premium version of Grammarly. The Grammarly Tool can provide writers with suggestions with an excellent English grammar structure. Considering that if the author is wrong and keeps using the wrong one, this is very detrimental to the author. This is the use of this software to sharpen writers in understanding its usefulness is very useful. Other supports that can be used from this application, such as when the author writes an idea on paper, tends to be ideally controlled, such as the writer repeating to do it differently not to repeat if it is wrong. In this point, Gain et al. (2019) noted that the usage of Grammarly's virtual application could help with spelling checker tools at the work of academics and sciences. This tool can say in many ways so that the writing looks perfect. Then this application also functions very well to improve writing styles such as writing or guiding students to write concise language briefly in paragraphs with precise and concise sentences.

So writing in the academic field must be concise to the point and coherent. Wilkes et al. (2015) said that in developing content literacy and academic composition skills through the group work design of an assessment task for first-year engineering students. Then Grammarly also suggests using vocabulary variations. Moreover, do not repeat the same thing even though the concept may be the same, but the writing needs tool support automatically, giving writing a different vocabulary. This is what is right, and this is what will make the writing support the writer to avoid putting like the same vocabulary, the same word, the same time, the same structure in the same context. This application tool gives some suggestions. That is what relevant grammar application software does or responds to what academic writing styles are like. One of them is a Grammarly tool to improve the quality of writing or English academic style. In academic writing also keeps formal language different from everyday conversation. If you speak the formal language, you will automatically be advised to use such formal vocabulary like Bintang sentences and yes words, of course, vocabulary words that you cannot use. Like every day and like in social conversations like 
conversations outside the field, this is formal so take care. Academic writing must be efficient because academic writing must be clear, focus briefly, and be written in a good structure, of course, placed like studies or evidence from previous research to understand what the author is doing efficiently. Of course, sentences should not be too complicated because when thinking is written in very complex sentences. It will be challenging for the writer to understand it so that academic works do not need to use long sentences and very complicated words and vocabulary. Wischgoll (2016) suggested that combining one cognitive and one metacognitive strategy improves academic writing skills. Again, this is why academic writing has reason to be efficient at writing on the academic writing scale so that we must work with grammar right. Then academic papers do not want to fail in the knowledge of giving correct punctuation. Then like writing, he must be good at paraphrasing. Writers work, so when a tool reads a writer's ideas like yes paraphrasing, it is necessary to be good at spelling; that is why the Grammarly application is used by professionals and academics when working on formal writing.

When a writer thinks about writing skills, he can improve them from scratch until he has to learn from the basics like this, which is right in real work, and reading further is like finding collaborative writing. He should go to more workshops then choose an excellent good writing model. Then if the writer can write, that meets the requirements of other writers. Such writers make more friends who do good academic writing - for example, going to improve the quality of writing. So he does not have to ask how someone or an outsider learned to write. Some beginners can learn to improve their writing to be the best academically because anything academic writing takes a long time to prepare.

Now the author is asking why such academic writing should have such a suitable style? It is essential because, of course, it is essential. After all, many experts say that academic writing has a purpose. The aim is to express the thoughts in academically correct language that is easy for the reader to understand. In the correct academic language, the author can use written English to communicate his academic knowledge. So traditional science skills, so you have to be able to use the writing in an academic style, he must be able to convince the audience so that others can quickly learn the writing you think through convincing writing, okay writing and then it must be clear so doing it is part of the way to convince readers.

Writing in academic should have right style academic writing also have has benefited water let us say being like a writer and he thinks he can be easily understood because he writes it in academic writing fashion. So if he is doing like university work, he gets excellent when he is doing good writing in excellent will be up if he is not a student anymore, he is on the job or career. Of course, if he can communicate in writing form successfully support by Google. Let us say if he a lectures university he can conduct his research and then his ability to write his journal, his paper article, and then it is is a strength for him strong reason for him to be right that is a benefit.

As a writer works to produce good academic English, he needs way his simple way to improve academic English besides using the useful application to improve his academic writing. Various expert has successfully suggested several approaches, particularly English language authors they say expanding vocabulary is much more critical than another way. Let us say how he can organize a much different variety of words with different words but the same meaning. When he is in contact, he can use correct words do not repeat the same word, so he has to develop his work the fluffy vocabulary in terms of structure in terms of its farm in a sentence in terms of meanings he spends the vocabulary for meaning for the written form. For, let us say spelling of things, he has to learn words using it in the contract, not depending on the same kind of work for every different contact.

Apart from expanding the vocabulary to improve his English writing, there are other ways also crucial for him to be an active reading reader. So, he can practice his English through the more read, the better idea you can put in the contract so regularly read from various reading or database information so learn to read and then put in words and then please and then share this another way to improve academy English choose the right book or article, or any particular or any platform can improve English in.

If he is right in vocabulary, he is good at reading; of course, he needs to improve the grammar. Thankfully, a lot of grammatical check grandma take an improvement Grammarly to take a mistake correction software available online. It can use to improve the grammar then better grammar will have excellent English writing, for example, use the correct and use correct grammar use correct punctuation and be clean and writing and fluence a good in Thatcher will be useful and writing so do it again after he writes and then improve it so increase by the day. Moreover, the other way he can do it is to keep doing it repeatedly, eat again, and do not feel happy to improve it; write it, sit in front of the computer, and prepare something to read something to write something to eat something to practice like stop it. 


\section{Method}

The methods and materials we use in this review study are systematic reviews to understand how the Grammarly application that academics and professionals have widely used can be appropriately understood to improve writing skills academically. The first step is collecting data from online search literature sources and visits to 40 scientific journals that discuss Grammarly themes from different perspectives. Next, we analyze it by involving the Kedean system, drawing conclusions that fulfill the principles of validity and reliability of the findings that have answered the question. Our search for publications is dedicated to publications between 2010 and 2020 so that the data we display is still updated. While the design of this study, we choose a qualitative descriptive method that is explorative and phenomenological. This study relies on current data from the time of this study we were conducting; it was still in a pandemic atmosphere, so we used the data from the previous penetrative findings. To obtain guidance, we followed qualitative experts such as Bowler et al. (2018) with the theme of their study "Exploring youth informationseeking behavior and mobile technologies through a secondary analysis of qualitative data."

\section{Result}

Irfan et al. (2020) study the innovative information application on scholastic composing English schooling study program understudies. Mechanical information does not generally give benefits in scholarly composition. It might influence the author's attitude to take an easy route in completing and checking their composition. The discoveries showed that the members applied innovative information on scholastic, especially discovering references and organizing thought. The members had a few issues in applying innovative information in academic writing.

Aidil (2021) investigated students' perception of the "Grammarly application" students' effectiveness concurred that Grammarly was valuable for learning scholastic composition. The information showed that this program had given free openness, programmed amendment, and helpful input. Four parts of scholarly composing that helped the program were intricacy, objectivity, custom, and supporting. Two disadvantages were found in this program, like misdirecting and over-checking. The discoveries were talked about into two points dependent on the exploration questions and afterward dissected distinctly. The investigation was distributed in the online diary of the University of Islam Negeri Ar-Raniry.

Rosyada (2016) studies how to improve students' basic tense in writing description text using the Grammar checker Understudies of SMK IPT Karangpanas were shown utilizing the Grammar Checker Application. The exploratory gathering's mean score improved from 64.6 to 80.27. The benchmark group's score improved between 64,73 to 77,67 . Utilizing the t-test equation, the $\mathrm{t}$-esteem was 3,375 and the $\mathrm{t}$-table for $\sigma=5 \%$ was 2,0017 . The author infers a critical distinction of showing Simple Present Tense recorded as a hard copy spellbinding content between understudies who were educated with Grammarly Grammar checker Application and the individuals who were showing utilizing traditional instructing. He proposes that educators utilize this media to show Simple Present Tense and apply it in their next homeroom exercises.

Tacoamán Portilla (2019) tested virtual composing guide programming to improve scholastic composing abilities (Master's proposal, Universidad Técnica de Ambato. This examination planned to investigate the impact of a virtual composing mentor programming on improving the English scholarly composing abilities in a gathering of SuperIntensive Level understudies at the Languages Institute Espe-Inca Branch, Universidad de lasFuerzas Armadas, Quito, Ecuador. An example of this exploration was 25 understudies. This examination depended on subjective and quantitative methodologies. A semi-test configuration, otherwise called when configuration, was actualized. This examination utilized a Classroom Action Research plan. It was done for about a month and a half. A poll, a perception, a pre-test, and a post-test were utilized to gather the information. The virtual composing guide programming Grammarly was utilized in the English class to create scholastic composing abilities. The post-test showed improvement in understudies' scholastic composing abilities because of the exercises executed in the class.

Frankenberg-Garcia et al. (2019) building up a composing collaborator to assist EAP journalists with collocations progressively. Journalists who need to quit writing to look into a word can be diverted from getting their thoughts down on paper. ColloCaid project plans to address these issues by coordinating data on collocation with word processors. We share the examination supporting the task's underlying improvement and framework the subsequent stages in the exploration. We are gathering a lexicographic information base we are accumulating to help the collocation needs of amateur clients of English for Academic Purposes (EAP).

Nova (2018) studied using Grammarly to evaluate academic composition through a narrative study on English class learning experience. This analysis was structured to consider the qualities and disadvantages of the Grammarly program as a mechanized composing evaluation program for the assessment of scholarly composition. The 
examination investigated three Indonesian postgraduate understudies' encounters by directing meetings and documentation. The outcome showed that this program has furnished helpful shading coded criticism with clarification and model. Notwithstanding, a few admonitions were additionally found in this program use, like a few deluding inputs, shortcomings on recognizing the kind of English and reference rundown, and absence of setting and substance assessment experienced. Further examination on the proficiency of the criticism in improving understudies' composing quality is required.

Huang et al. (2020) studied the effectiveness of using Grammarly to develop students' English academic writing skills. This contextual analysis's motivation was to examine the viability of utilizing Grammarly in EFL composing during a 16-week trial period at a four-year college in China. The outcomes uncovered that understudies' composing execution altogether expanded all through the multi-week intercession. This recommends that applying Grammarly recorded as a hard copy class is a viable methodology for EFL understudies in creating composing abilities.

ONeill \& Russell (2019) studied Grammarly system checking to help or prevention? Scholastic Learning Advisors' perception of an on-line academic language checker. An investigation into robotized input innovation in Australian tertiary organizations has zeroed in on the language structure checker, Grammarly. This investigation expands on ONeill \& Russell (2019) examination of understudy views of Gram Marry. Scholastic Learning Advisors' (ALAs) view of the program was contrasted with customary input strategy utilizing Word. For 13 out of 15 articulations, the counsels utilizing Gram Marly concurred with all assertions about their language guidance's adequacy. It is suggested that Gram marly ought to be utilized as an input apparatus for tasks related to an ALA, yet just whenever utilized couple with a traditional criticism instrument.

Gain et al. (2019) studied the usage of Grammar-Online syntax and spelling checker platform at the Wellness Science Library, Manipal Academy of Higher Education, Manipal: Grammarly is an online phrase structure and spelling checker system obtained from the Health Science Librarian, Manipal Academy of Postsecondary Education. The lion's share of the respondents who took an interest in the investigation was utilizing Grammarly for Microsoft Office. The Study saw that clients utilize the device for various purposes like composing research papers, papers, postulations, books, reports, and course papers. The vast majority of the clients utilized this apparatus due to the limit of Microsoft word as found in the Study. Grammarly coordinates with Microsoft Office to show definitions and equivalents through double-clicks and get context-oriented spelling and syntax ruins. It is one of the instruments bought in by the Health Sciences Library to support up the scholarly composition.

\section{Discussion}

This section will discuss the main findings of this study, which aims to understand the evidence of the Grammarly software application's effectiveness in improving the quality of academic and other organizational writers' skills that involve writing activities, both personal and professional writing. The findings from the literature and publications that we have reviewed have proven how useful and useful this digital-based application is. For example, the findings of Irfan et al. (2020) who successfully studied how students of English school study programs have used this innovative application of writing technology to prepare academic works, are essential. Mechanical information generally provides benefits in scientific composition. This application can influence the writer's quality and attitude for the right way to complete and check the composition. However, this application has shown that students can apply innovative information about scholastics, especially finding references and adjusting their exposure to thoughts. The participants had a few problems applying innovative information in academic writing; namely, this application is the speedy way of working so that beginners will be overwhelmed by balancing and understanding the entire content of the writing after being corrected by the Grammarly application, especially for those who pay a premium price. Wajdi et al. (2018) also presented this original proof in the Grammarly Premium Version tutorial format. Meanwhile, support and proof of this digital online application's effectiveness are, for example, Akorede (2020) which proves in the 2020 Grammarly Review which says "Do not Buy Without Reading This."

Despite the findings that support our hypothesis, it turns out that other findings have succeeded in proving that the Grammarly application does not only provide new help to users in the academic environment, but some words do not help. The reason, according to ONeill \& Russell (2019) is the Grammarly system examination to help but also prevent the perception and understanding of scholastic learning advisors about online academic language correction. Their evidence of robotic input innovation in Australian tertiary organizations has focused on examining language structures. According to ONeill \& Russell (2019) checking this machine regarding the views of students being lazy to think critically is right. They suggest that this Grammarly application be used as an input tool for academic-related tasks. Not all correction models are used in conjunction with traditional criticism tools. Other evidence was said by 
Park (2019), Rachmawati et al. (2020) who studied an AI-based English grammar checker vs. human raters in evaluating EFL learners' writing.

As for this application's impact after a long time of use, it should be noted that the dependence on such a large amount of digital amnesia on the user, however, if this application is a balance between self-efficacy with practical solutions. This application will be of fair use if used according to reasonable limits under experts' direction both in language and other content. Many users discuss what they are doing with the application. Many do not remember and do not understand deeply. Another balance between benefits and disadvantages with this Grammarly check application in the current academic writing space after the program and asking students about correct writing improvements.

\section{Conclusion}

Finally, we can summarize the results of this study after discussing the main findings where our goal is to understand how effective the use of the Grammarly application is in programs to improve the quality of writing work in an academic environment. By investing, the experts we have reviewed have provided the results of their studies, among others. Those who support them say that the Grammarly application is handy because of its effectiveness in providing corrections and other checks to accommodate many linguistic issues in writing academic standards and the outside academic world.Those who are neutral advise o use this application as needed or as a stone tool open it completely. While those who do not support them instead of saying it is very disadvantageous to remember students or openly.

\section{Acknowledgments}

We, the authors, thank all colleagues for their support in the form of initial input when our project started, then corrective input, and good feedback from the beginning, the processing period to completing writing and reporting. Likewise, the university's funding support and a beneficial guidance with the title "Effectiveness of Online Grammarly Application in Improving Academic Writing; Review of Experts Experience."

\section{References}

Aidil, T. M. (2021). Exploring Students' Perception On The Effectiveness Of "Grammarly Software" In Academic Writing [PhD Thesis]. UIN Ar-Raniry.

Akorede, S. (2020a). Grammarly Review 2020-Don't Buy Without Reading This!

Akorede, S. (2020b). How to Add Grammarly to Microsoft Word in 2020 (Guide).

Amelia, L. C. H., \& Abidin, M. J. Z. (2018). Young ESL Learners' Perception on the Effects of Using Digital Storytelling Application in English Language Learning. Pertanika Journal of Social Sciences \& Humanities.

Bailey, D., \& Lee, A. R. (2020). An Exploratory Study of Grammarly in the Language Learning Context: An Analysis of Test-Based, Textbook-Based and Facebook Corpora. TESOL International Journal, 15(2), 4-27.

Barrot, J. S. (2020). Integrating Technology into ESL/EFL Writing through Grammarly. RELC Journal, 0033688220966632.

Băutu, E., \& Băutu, A. (2020). Developments on PlagZap, the Fast and Free Textual Plagiarism Detection Solution for Universities. Logic Journal of the IGPL.

Bowler, L., Julien, H., \& Haddon, L. (2018). Exploring youth information-seeking behaviour and mobile technologies through a secondary analysis of qualitative data. Journal of Librarianship and Information Science, 50(3), 322-331.

Chen, X., Xie, H., \& Hwang, G. J. (2020). A Multi-Perspective Study on Artificial Intelligence in Education: Grants, Conferences, Journals, Software Tools, Institutions, and Researchers. Computers and Education: Artificial Intelligence, 100005. https://doi.org/10.1016/j.caeai.2020.100005

Cavaleri, M. R., \& Dianati, S. (2016). You want me to check your grammar again? The usefulness of an online grammar checker as perceived by students. Journal of Academic Language and Learning, 10(1), A223-A236.

Ellingson, J. E., \& Noe, R. A. (2017). Autonomous learning in the workplace. Taylor \& Francis.

Finlay, L. (2020). How to write a journal article: Top tips for the novice writer. European Journal for Qualitative Research in Psychotherapy, 10, 28-40.

Frankenberg-Garcia, A., Lew, R., Roberts, J. C., Rees, G. P., \& Sharma, N. (2019). Developing a writing assistant to help EAP writers with collocations in real time. ReCALL, 31(1), 23-39. 
Gain, A., Rao, M., \& Bhat, S. K. (2019). Usage of grammarly-Online grammar and spelling checker tool at the health sciences Library, Manipal Academy of Higher Education, Manipal: A study. Library Philosophy and Practice, 1-13.

Ghufron, M. A. (2019). Exploring an Automated Feedback Program 'Grammarly'and Teacher Corrective Feedback in EFL Writing Assessment: Modern vs. Traditional Assessment. ELLIC. ELLiC 2019: Proceedings of the 3rd English Language and Literature International Conference, ELLiC, 27th April 2019, Semarang, Indonesia, 307.

Hiremath, B. N., \& Patil, M. M. (2020). Enhancing Optimized Personalized Therapy in Clinical Decision Support System using Natural Language Processing. Journal of King Saud University-Computer and Information Sciences. https://doi.org/10.1016/j.jksuci.2020.03.006

Huang, H.-W., Li, Z., \& Taylor, L. (2020). The Effectiveness of Using Grammarly to Improve Students' Writing Skills. Proceedings of the 5th International Conference on Distance Education and Learning, 122-127.

Irfan, I., Sofendi, S., \& Vianty, M. (2020). Technological knowledge application on academic writing English education study program students. English Review: Journal of English Education, 9(1), 157-166.

Koltovskaia, S. (2020). Student engagement with automated written corrective feedback (AWCF) provided by Grammarly: A multiple case study. Assessing Writing, 44, 100450. https://doi.org/10.1016/j.asw.2020.100450

Kaushik, H. M., Eika, E., \& Sandnes, F. E. (2020). Towards Universal Accessibility on the Web: Do Grammar Checking Tools Improve Text Readability? International Conference on Human-Computer Interaction, 272-288.

Lassoued, Z., Alhendawi, M., \& Bashitialshaaer, R. (2020). An Exploratory Study of the Obstacles for Achieving Quality in Distance Learning during the COVID-19 Pandemic. Education Sciences, 10(9), 232. https://doi.org/10.3390/educsci10090232

Manullang, S. O., \& Satria, E. (2020). The Review of the International Voices on the Responses of the Worldwide School Closures Policy Searching during Covid-19 Pandemic. Jurnal Iqra' : Kajian Ilmu Pendidikan, 5(2), 1-13. https://doi.org/10.25217/ji.v5i2.1036

Nova, M. (2018). Utilizing grammarly in evaluating academic writing: a narrative research on efl students'experience. Premise: Journal of English Education and Applied Linguistics, 7(1), 80-97.

ONeill, R., \& Russell, A. (2019). Stop! Grammar time: University students' perceptions of the automated feedback program Grammarly. Australasian Journal of Educational Technology, 35(1).

Park, J. (2019). An AI-based English grammar checker vs. Human raters in evaluating EFL learners' writing. Multimedia-Assisted Language Learning, 22(1), 112-131.

Parra, S. (2016). Use of student created video podcasts to promote foreign language grammar acquisition in middle school.

Qassemzadeh, A., \& Soleimani, H. (2016). The impact of feedback provision by Grammarly software and teachers on learning passive structures by Iranian EFL learners. Theory and Practice in Language Studies, 6(9), 18841894.

Rachmawati, M., Widjajanti, S., Ahmad, A., \& Aslan, A. (2020a). The English Camps as Method of Promoting Fun English at Elementary School Level in Indonesia. Tapis: Jurnal Penelitian Ilmiah, 4(2), 174-182. https://doi.org/10.32332/tapis.v4i2.2563

Rosyada, N. A. (2016). Improving students simple present tense in writing descriptive text using grammar checker application in the tenth grade students of smk ipt karangpanas in the academic year of 2015/2016 [phd thesis]. Universitas Negeri Semarang.

Susskind, R. E., \& Susskind, D. (2015). The future of the professions: How technology will transform the work of human experts. Oxford University Press, USA.

Syafi'i, A. (2020). Grammarly: An Online EFL Writing Companion. ELTICS: Journal of English Language Teaching and English Linguistics, 5(2).

Tacoamán Portilla, M. G. (2019). Virtual writing tutor software in the development of academic writing skills [Master's Thesis]. Universidad Técnica de Ambato. Dirección de Posgrado. Maestria en la ....

Taylor, A. M. (2016). The future of the professions: How technology will transform the work of human experts (Book Review). Social Work Education: The International Journal.

Ventayen, R. J. M., \& Orlanda-Ventayen, C. C. (2018). Graduate students' perspective on the usability of Grammarly® in one ASEAN state university. Asian ESP Journal, 14(7.2).

Wajdi, M. B. N., Prasnowo, M. A., \& Rahim, R. (2018). Tutorial Grammarly Versi Premium.

Wilkes, J., Godwin, J., \& Gurney, L. J. (2015). Developing information literacy and academic writing skills through the collaborative design of an assessment task for first year engineering students. Australian Academic \& Research Libraries, 46(3), 164-175. 
130

Wingate, U., \& Harper, R. (2021). Completing the first assignment: A case study of the writing processes of a successful and an unsuccessful student. Journal of English for Academic Purposes, 49, 100948. https://doi.org/10.1016/j.jeap.2020.100948

Wilmore, M., \& Willison, J. (2016). Graduates' attitudes to research skill development in undergraduate media education. Asia Pacific Media Educator, 26(1), 113-128.

Wischgoll, A. (2016). Combined training of one cognitive and one metacognitive strategy improves academic writing skills. Frontiers in Psychology, 7, 187.

Xie, Q. (2019). Error analysis and diagnosis of ESL linguistic accuracy: Construct specification and empirical validation. Assessing Writing, 41, 47-62. https://doi.org/10.1016/j.asw.2019.05.002

Xie, Z., \& Yang, J. (2020). Autonomous Learning of Elementary Students at Home During the COVID-19 Epidemic: A Case Study of the Second Elementary School in Daxie, Ningbo, Zhejiang Province, China. Best Evidence of Chinese Education, 4, 535-541. https://doi.org/10.15354/bece.20.rp009

Zhang, X. (2020). The Relationship of Coaching Leadership and Innovation Behavior: Dual Mediation Model for Individuals and Teams across Levels. Open Journal of Leadership, 9(1), 70-83. https://doi.org/10.4236/oj1.2020.91005 